\title{
Nurses' Encountered Challenges with Patient-centered Care in Rural Primary Health Care Centers: A Case Study of Nigeria
}

Adepeju Lateef ( $\sim$ princessadepejuu@gmail.com )

University of KwaZulu-Natal - Howard College Campus https://orcid.org/0000-0003-1342-565X

Euphemia Mbali Mhlongo

University of KwaZulu-Natal College of Health Sciences

\section{Research article}

Keywords: Patient-centered care, implementation, challenges, nurses, Primary Health Care, healthcare service, nursing caring, and Nigeria

Posted Date: January 15th, 2021

DOI: https://doi.org/10.21203/rs.3.rs-144186/v1

License: () (7) This work is licensed under a Creative Commons Attribution 4.0 International License. Read Full License 


\begin{abstract}
Background

Globally, patient-centered care has become the focus of the healthcare system. Therefore, it is imperative to note that patient-centered care seeks to empower partnering approaches to primary health care and has recently gained prominence in nursing practice and applied nursing research. However, nurses are faced with numerous challenges in achieving the desired results and objectives related to Patient-centered care in the Primary Health Care system. Thus, the study explores the negative factors influencing the implementation of Patient-centered care in rural Primary Health Care facilities in Nigeria.
\end{abstract}

\title{
Method
}

A qualitative participatory action research design was used. Data collection was conducted with the nurses from Primary Health Care facilities through individual interviews and focus group discussions. Data saturation was achieved with 35 participants from 30 Primary Health Care facilities in Osun State, Southwest Nigeria, using a purposive sampling technique. All interviews were audio-recorded, which were later transcribed verbatim and analyzed using a thematic content analysis approach. NVivo 12 software was used for data management.

\section{Results}

The results from this study was categorized into two: organizational factors and individual factors. Five themes that emerged from the study include: inadequate management support, insufficient operational skills and knowledge /equipped learning, increased workload and time constraints, health personnel readiness, dearth enthusiasm for change and accountability of the staff.

\section{Conclusion}

The results of this study show that nurses encountered diverse challenges in the implementation of patient-centered care. To improve healthcare delivery quality in the Primary Health Care facilities, there is a need to reinforce adequate management support, education, training, and the nurses' internal motivation to achieve a transformative healthcare outcome.

\section{Background}

Patient-centered care (PCC) has been presented as one of the most rapid and robust approaches for considerable reform effort that is directed towards healthcare delivery, reimbursement, and primary health [1-6]. These diverse efforts have been initiated by various constituents such as professional organizations, major employers in healthcare, medical insurers, state governments, and non-profit organizations [7]. Transformation to PCC requires an additional shift in personnel involved with Primary health facilities (PHC) as caregivers and units which bear greater responsibility and accountability [8] Therefore, this study aimed is to explore the negative factors influencing the implementation of PCC in PHC facilities in Osun State, Nigeria.

According to Engel George, an American Psychiatrist recommended PCC as a new medical model in medicine [9]. This was due to the unparalleled care between the psychosocial and biological challenges that has been a struggle but needs to be reconciled within human beings. Therefore, achieving evidencebased approaches to healthcare intervention is a significant challenge, leading to a discrepancy in health care across the world [10]. Although patients improved satisfaction, quality healthcare, health outcomes, reduced cost of health care, and reduction in the health care disparities have been demonstrated in developed countries [6,11], however, in low and middle-income countries (LMICs) such as Nigeria multiple difficulties such as literacy, political instability, make the PCC principles more challenging to implement, deliver and optimize [12,13]. As a result, there has been a need to develop a holistic approach to understanding the 'What' and 'Why' for healthcare and the 'How' [14-16].

\section{Challenges Facing Implementation of PCC}

PCC has been observed to defy a series of incremental changes. In the last two decades, phenomenal theoretical development emphasizes the quality of PHC with healthcare facilities practices [17]. There is a need for leadership skills compared to authoritarianism. This quality can be achieved through healthcare provider expansion of clinical focus from single patients to more proactive population-based, particularly for the chronic and terminally ill patients and the kind of preventive services being offered $[18,19]$. Additionally, practitioner-patient relationships should shift and lean towards a relationship-centered partnering to achieve patient-oriented goals compared to adherence to clinical guidelines [20-22].

Another area posing a challenge to PCC is technological changes and incorporate them into the PHC system to benefit healthcare providers and patients. New technology is more complicated and is time-consuming to implement than most organizations and healthcare managers envisioned. Technical support is

practical; for example, the case of electronic medical records (EMR) is marketed as a tool for entering and storing medical records. However, it has been shown to require a complicated workaround and sometimes becomes extremely difficult and awkward to activate [23-26]. Technological changes also require a redefinition of the work process before implementation, thus floundering in practice redesign.

\section{Cost implications of Patient-centered care}

PCC's implication in reducing the total cost of primary health care is still a subject of debate. The reduction of healthcare cost remains unanswered, although there is growing evidence of a favourable impact of PCC achieving the triple aims of population health, improved care experiences, and lower cost of health care [27-30]. 
Based on the available literature, there is a strong basis to recognize the benefits of PCC model implementation in a broader context to reap its benefits [31, 32]. However, there are no studies that can conclusively prove the efficacy of the PCC model in the healthcare system. The available literature in this area will provide a framework for understanding how best the PCC model can be implemented effectively in different environments and how it could be measured and evaluated.

However, PCC's potential impact on the cost of care remains unclear and debatable since the cost is not explicitly the goal of PCC [31, 33]. In fact, PCC may increase the cost of care, especially in the short-term, as it employs greater preventive care use. Fortunately, this short-term increase in the cost of care is offset by the large decrease in acute care use which is linked to poor access to early primary health care. In other words, PCC focuses on the "upstream" in the whole care process. For instance, the PHC clinic visits, provision of preventive care and comprehensive chronic care, and care coordination to reduce the "downstream" emergency department visits and acute admissions [28]. It is imperative to note that most of the research findings covering PCC's cost implications tend to focus on value achieved from PCC implementation as a model in the PHC. Few studies have documented direct cost to deliverance and PCC implementation to medical practice functions [34].

\section{Primary Health Care System in Nigeria}

Quality healthcare services are essential to the population in Nigeria. The Nigerian healthcare system is divided into three-tiers: tertiary level, secondary level, and PHC level [35]. All these tiers are involved in all aspects of the healthcare system functions: stewardship, financing, and service provision. In terms of operations, the tertiary level operates from the federal ministry of health $(\mathrm{FMOH})$, the secondary level operates from the State ministries of health (SMOH), and the Primary Health Care which is at the grassroots operates from the local government health care (LGHC). Also, the local government sustains the PHC facilities in the communities [35,36]. According to the World health organization (WHO), the key to the achievement of health for all, as identified in the international Alma-Ata Declaration of 1978 is PHC [37]. However, Nigeria is yet to attain health for all in spite of the fact that several years have passed. PHC was adopted in Nigeria in 52 local government areas (LGAs) during Olikoye Ransome-Kuti between 1986 and 1992 as models. As the population health outcomes improved, PHC was then extended to all the LGAs [38, 39]. From literature, there are approximately 30,000 PHC facilities across the 36 states in the Federal Republic of Nigeria [40]. Out of these PHC facilities, only $20 \%$ are functioning well [40, 41]. Moreover, a strong PHC improves the management of noncommunicable diseases (NCDs), reduce mortality from NCDs, reduce infant and under-five mortality, reduce maternal mortality, and increase life expectancy at birth [42].

Usually, at the grassroots level of the healthcare facilities, the objectives are not clear and sometimes may not have been formulated [43-45]. Thus, PHC needs to be evaluated particularly healthcare service delivery [43]. In addition, only one doctor serves in the whole local government area in leaving the majority of the PHC clinics which are located in the rural areas under the care of the nurses and community health workers in Nigeria [46]. Also, poor healthcare policies are imperatively affecting the availability of effective quality healthcare service delivery in the PHC facilities, causing serious challenges encountered in some of the communities and the country at large $[47,48]$. In terms of accessibility and availability of manpower, most rural PHC facilities in Nigeria function below standards [46, 49]. Hence, using a simple intervention model as a guide to promote healthcare and prevent diseases may be missing in most of the PHCs in Nigeria. The nurses' knowledge and judgment at the PHC in using patient-centered care principles in the PHC facilities will evaluate participation. This approach will be of great value since the experience is from the grassroots.

As such, conducting this study will add value to the limited literature and documented policies on the healthcare delivery system in Nigeria. In addition, this study will also address the integration of PCC into the PHC setting, a study with very limited literature on the Nigerian healthcare system.

\section{Materials And Methods}

A qualitative research study design that employed a participatory action approach to understanding the social reality [50] from the perspective of the nurses working in the rural PHC settings were used to explore PCC implementation in the PHC facilities. This approach gives a richer understanding and more insight into social phenomena of interest [51]. Hence, it allows the researcher to generate an in-depth understanding of the PCC concept in PHC from the nurses' perspectives in the context of the Nigerian healthcare system.

\section{Study area}

The study was conducted in the PHC settings located in Osun State, Southwest, Nigeria. Osun state is one of the states in the Southwest, with its capital in Oshogbo and a population of 4,705,589 [52]. Southwest was purposively selected from the six geopolitical zones in Nigeria, while Osun state was randomly chosen from the six states in the zone through the ballot. Osun State is divided into three Senatorial Districts: West, Central, and East. These districts are further sub-divided into two zones each. Osun West: Ede and Iwo zones; Osun Central: Oshogbo and Ikirun zones and Osun East: Ilesha and Ife zones. These zones comprise of thirty (30) local government areas [53]. The study was conducted in all three (3) districts. The local government and the PHC from these 3 districts were selected randomly after listed all the PHC and the LGAs separately in a sampling frame.

\section{Population, Sampling techniques, and recruitment}

The target population for this study comprised nurses who work in rural PHC as a community health nurse. This was based on the assumption that this group of nurses was capable of implementing the PCC concept for quality healthcare service delivery. A purposive sampling technique was used. Participants were recruited for this study based on the following criteria: 
(a) Participants had to be a registered nurse

(b) Participants must have been working in the rural PHC

(c) Participant must have had a minimum of one-year experience in the community

(d) Participants must be providing direct healthcare service to patients.

Participants were recruited through the PHC facilities where the study took place. The data collection for the study reached saturation with a population size of 35 for individual interviews. In addition, the FGD used was comprised of seven nurses in each group based on their availability. This sample size was based on the principle of theoretical saturation [54] that follows the process of gathering and analyzing data until it reaches a point of no new idea or information is observed. The nurses who participated in the study comprised of 7 males and 28 females with different age groups who had varied nursing qualifications and years of working experience as shown in Table 1.

Table 1

Characteristics of the participants

\begin{tabular}{|llllll|}
\hline Participants ID & Frequency & Working experience & \multicolumn{2}{l}{ Academic Qualifications } & Percentage \\
\cline { 4 - 6 } & & & RN,BNS & RN, RM and RPHN & (\%) \\
\hline P1-P9 & 9 & $2-10$ & 8 & 1 & 25.7 \\
\hline P10-P11 & 15 & $11-15$ & 7 & 8 & 42.9 \\
\hline P12-P31 & 7 & $16-18$ & 1 & 6 & 20.0 \\
\hline P32-P35 & 4 & $19-31$ & 0 & 4 & 11.4 \\
\hline
\end{tabular}

\section{Data collection and data analysis}

Interviews were conducted between October 2018 and February 2019. A qualitative approach was used to acquire data from the participants through an individual in-depth interview and Focus group discussion (FGD). Open-ended questions and probing were used to obtain nurses' perceptions of the phenomena of interest. An inductive approach [55] was used to analyze the data. All interviews were audio-recorded and transcribed verbatim. These recordings were read numerous times to familiarize ourselves with the information gathered. NVivo 12 software was used for data management. The organization of the codes was based on relevant information identified from the data. These codes were developed into themes and sub-themes guided by thematic content analysis [56, 57].

\section{The rigor of the study}

The term rigor or trustworthiness is used to explain the validity and reliability in qualitative studies [58, 59]. This refers to the rigor of the data and the degree to which a researcher could influence the readers that the study is worthy $[60,61]$. The four criteria that qualitative researchers considered in maintaining the trustworthiness of the study, as proposed by Guba [62], is employed in this study [63]. These includes: credibility, dependability, conformability and transferability [63].

Credibility: It refers to the accuracy with which the data provided by the participants were interpreted [61, 64]. To ensure the credibility of this study, individual in-depth interviews and FGD were adopted to obtain information from the participants. The researcher spent adequate time with the participants in order to understand them better and gain insight into the phenomenon under study and their experiences during data collection. Each interview lasted for 15 to 30 minutes per participant. However, data saturation was ensured. Field notes were taken that noted gesture and other non-verbal cues. All interviews were audiorecorded for further analysis.

Confirmability: This is the extent to which data collected from the participants was analyzed objectively such that if another researcher examined the same data, they would get the same results $[60,61]$. The result of this analysis is not biased but a neutral reflection of the interpretation of the data obtained from interviewed participants. Confirmability was ensured through the audio-recorded and verbatim transcription of the interview. As such, the confirmability of this study was ensured.

Dependability: This refers to the stability and consistency of data obtained and the extent to which this data is dependable over time under different conditions. To ensure reliability, an inquiry audit was adopted to estimate the dependability of the results of the study through an inquiry audit and replication of research. A comprehensive description of the study setting, the technique for data collection and data analysis was presented in the results sections.

Transferability: This is the ability of the research findings to be applied to a similar situation and still yield similar results. This is the extent to which the findings and analysis can be applied to another similar research situation elsewhere $[58,65]$. Thus, transferability in this study was ensured by providing adequate data description, study setting, and socio-demographic characteristics of the participants. This could enable the public to evaluate the applicability of the data to other contexts. 


\section{Ethical approval and consent to participate}

Approval for this study was obtained from the University of KwaZulu-Natal Humanities Social Sciences Research Ethics Committee with Protocol reference number: HSS/1772/018D. In addition, permission was sought from Osun State Primary Health Care development board. Participants' participation was voluntary; participants provided both written and verbal consent for their participation. The confidentiality of this data is maintained by assigning a pseudo name to each participant. Lastly, no identity of the participants is revealed in this research.

\section{Results}

The themes generated from this study are as tabulated in Table 2. These are: inadequate management support, insufficient operational skills and knowledge or equipped learning, high workload and time constraints, health personnel readiness, dearth of enthusiasm for change, and accountability of the staff. A summary of these themes is also provided in the same Table 2.

Table 2

Summary of the themes and sub-themes

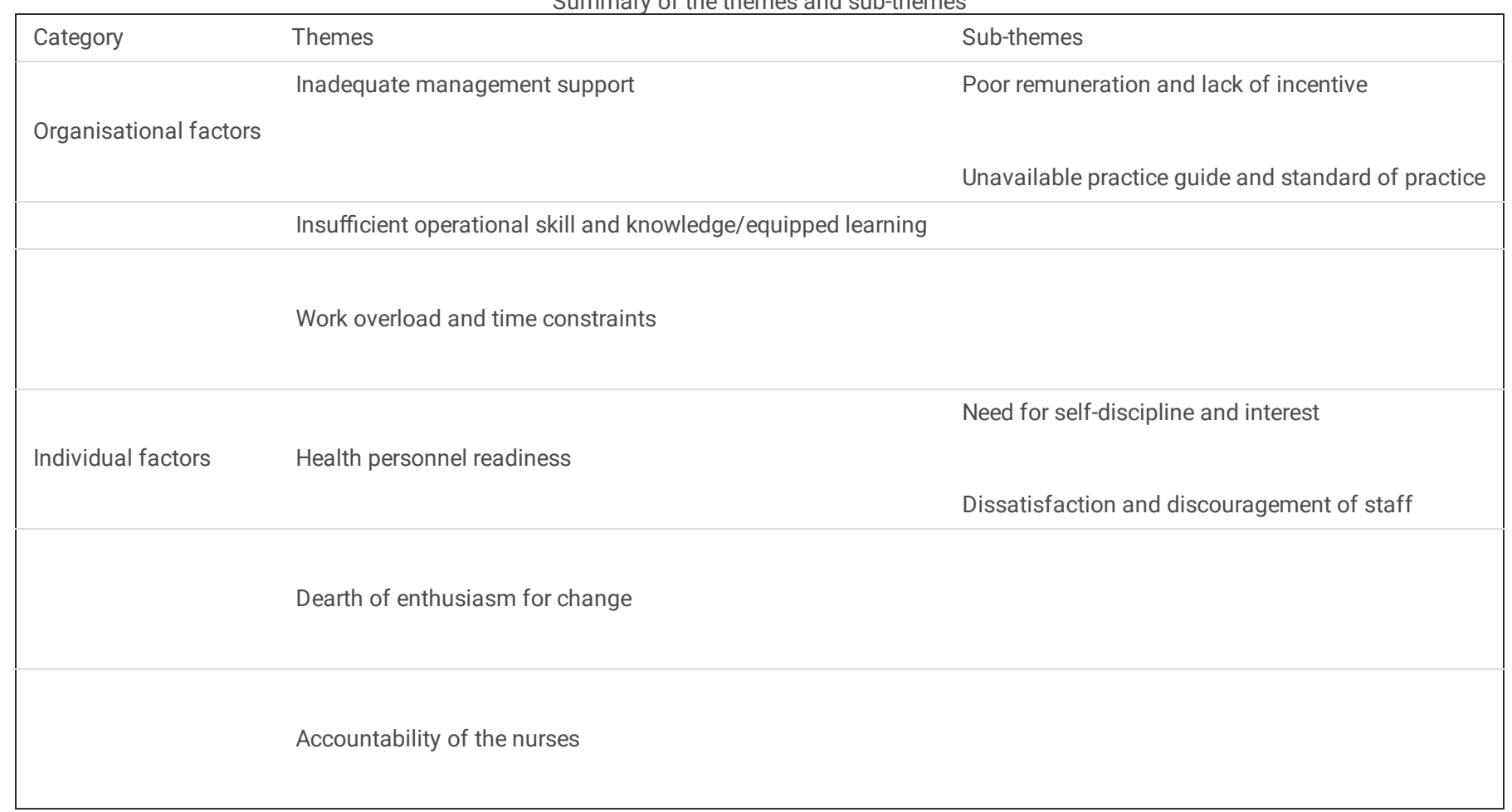

\section{Details of these themes and sub-themes are presented as follows:}

\section{Theme 1: Inadequate management support}

The following two sub-themes emerged under this theme:

(a) Poor remuneration and lack of incentive

(b) Unavailable practice guide and standard of practice

\section{(a) Poor remuneration and lack of incentive}

Participants reported that their welfare was not being taken into consideration at all. As a result, they were not motivated to deliver quality healthcare services to the community because they are poorly treated by the government. Nurses expressed that the government must first make them happy and comfortable by paying their salaries and incentives in a timely manner. Additionally, the PHC facilities were not well equipped and therefore required a complete improvement from the government to strengthen the healthcare system. This would in turn enhance the quality of healthcare services. The following is an excerpt from the audio recordings:

"Advocacy, if they pay us very well we will implement it. Good remuneration is necessary because the welfare of the health personnel matters. You see the staff are not well taken care of, our welfare is poorly attended to so we can't do better. I want to say that the nurses - the comfort of nurses - should also be 
taken into consideration (Nancy)."

"If the government do not participate enough to improve the remuneration of the staff in the healthcare centre there may be a challenge. A lot of constraints, a lot of compromises, we have from the government - from financing to human resources person, resources... most of these facilities you are seeing, we are not being supplied with anything. So most of the time we have to improvise... I think that is still a factor we can look into - incentive and encouragement (lyabo)".

\section{(b) Unavailable practice guide and standard of practice}

An unavailable practice guide and the standard of practice emerged as important, from the participants' narrative in this study. Even though healthcare services were provided to patients in the community, the nurses reported that policies, standards of practice and practice guides which are key in delivery of high quality healthcare services in PCC, were lacking. The nurses stressed the need to improve PHC facilities by providing an evidence-based working practice for nurses. These strategies would enhance effective PCC implementation leading to improve the healthcare outcome to the community. Below are the excerpts from the interviews:

"The challenge I see is the need to provide a written document... it could be in form of poster that could be pasted on walls to remind somebody working, so when you are working you look and it reminds you of something (Rose)".

"The design doesn't actually allow for total client-centered care in such a way... things are muddled up together, we are addressing a lot of people together at the same time, such that we are not really client-oriented in our healthcare service (Mary)".

"Then looking at the challenges we might say our knowledge bases are not the same so that might be a limitation to patient centered care in the primary health care system in Nigeria (Kola)".

\section{Theme 2: Insufficient operational skills and knowledge or equipped learning}

The participants reported insufficient operational skills and knowledge of PCC as one of the barriers to implementing its strategies. It was observed that PCC knowledge and skill are associated with effective implementation to improve the quality of nursing healthcare service in the rural areas. They revealed the importance of knowledge on the PCC concept as an asset to be given from the government to professional nurses even after they have been employed in the healthcare system. Participants revealed that failure to keep updating with current knowledge, skills and learning was a challenge to them in not being able to implement PCC. The extract below from the transcript is evidence:

"There is no empowering people for knowledge... If government can provide something like a workshop or seminar I think that can help again to achieve patient-centered care, because if we are not orientated towards patient-centered care even we nurses might not do it the way we ought to do it, but if we are all orientated, if we know it and are familiar with the components, the approaches then we can do something (Wole)".

"In terms of the technicality aspect of it, we might say Nigeria is still backward in the sense that when you are looking at the competence of the staff, the quality of service delivery to a client... we need more, adequate knowledge about patient-centered care (Kabirat)".

"...the knowledge and the skills can hinder the utilisation of the patient-centered care concept... I want to say lack of knowledge about the client-centered care... you can't practice what you don't know...you are not aware you will not be able to use it (Kudira)".

\section{Theme 3: Work overload and time constraints}

Work overload and time constraints emerged as a theme from the data. Participants reported excessive workload as one of the major hurdles to implementing PCC in the healthcare service in PHC settings. It was further mentioned that nurses faced a lot of physical and psychological stress due to the shortage of nursing staff in the PHC system. In addition, the nature of the environment and the workload made the quality of their nursing health care to be poor and the patients were not allowed to make decisions in the care process. This means that the current working environment in the rural PHC setting is not conducive for nurses to practice PCC. Related interview extracts below are evidence:

"Bureaucracy or let me put it that way, that is, if there are too many things to be done... If you have a lot to do like you have over 50 clients and it's only you. If you have enough hands you can easily practise PCC (Sadia)".

"So for an individual if the work load is bulky and we are busy, it may not be easy for us to follow PCC approaches and practise it (Joy)"

"If we nurses must practise this concept - our timing is very important because honestly we have a very large number of patient to attend to within a short period of time (Mary)"

\section{Theme 4: Health personnel readiness}

Health personnel readiness emerged as a theme with two sub-themes as follows:

(a) Need for self-discipline and interest 
(b) Dissatisfaction and discouragement of staff

\section{(a) Need for self-discipline and interest}

Participants identified self-discipline, interest and laziness as some of the hurdles to the implementation of PCC. It was further mentioned that for the PHC system to implement PCC, it would be crucial for nurses to develop enthusiasm with self-discipline in order not to continue undermining its potential to improving the quality of health care. The quotes below are a reflection:

"Laziness on the part of we, the nurses, to engage with patients... Interest is also important; some may not have interest in it like that...so lack of interest is a factor.... (Jide)".

"Lack of self-discipline, due to problems from government...because there are some things you can do, there are some things that you have knowledge of doing... (Kemi)".

\section{(b) Dissatisfaction and discouragement of staff}

Several participants who reported dissatisfaction and discouragement of the staff during interviews further expressed that underpaying rural nurses coupled with lack of incentives, lack of work balance, limited opportunities for career development and poor management of PHC resulted in poor healthcare service delivery. All these were mentioned to contribute to nurses' dissatisfaction and discouragement. As a result, delivery of quality healthcare services using PCC was negatively impacted. These extracts below are evidence:

"...if we have facilities and if it is not that the work is so much that five people are supposed to do it and only one person is doing it, definitely if there is division of labour, definitely nurses will adopt the method, it is a very good method and it will help nurses to know their patient better if there is improvement in the health of the patient... (Eunice)".

"There is an average amount of clients we are expected to see in the health facility, for example in the immunisations section let me use that as a standard, we are expected to see just about 30 or 40 . Just a facilitator, as I am expected to see 15 so if we are only two we are expected to see 30 people effectively but do you know we have people coming in tons of about 80 daily? (Winnie)".

\section{Theme 5: Dearth of enthusiasm for change}

Dearth of enthusiasm for change was reported by the participants during the data collection stage. It was also reported that the majority of the nurses were resistant to change. This prevalence among nurses was identified as a concern regarding PCC implementation. This is a potential consequence that contributed to the ineffective use of PCC. However, the readiness of the nurses to embrace change would enhance the healthcare outcome of the patients and improve healthcare service because nurses as individuals can promote PCC. These changes have the potential to increase the readiness to change among nurses and influence organisational interventions to promote PCC and the well-being of the healthcare providers which would inevitably lead to the high quality healthcare services needed. The extract below asserts this:

"I have seen what it could be so I know that many nurses are resistant to change that is the very first thing... there is this challenge of people not ready to change (Ade)".

"If you want to change the whole world you cannot change the whole world but you will realise that you, yourself, need to be changed - that's where to start... (Mariam)".

"Human beings naturally are resistant to change. The challenge I foresee is in the ability of the nurses to change their practice from what we have been practising since (Yinka)".

\section{Theme 6: Accountability of the nurses}

Participants reported professional accountability. It was expressed as taking responsibility for action by upholding the holistic standards on quality healthcare service of patient care as well as maintaining competency. The nurses further stated that it was important to ensure that the patient's interest was always considered first through collaboration and involvement in the decision making process. The nurse earned the patient's trust by sharing their thoughts willingly. The extract below is the evidence:

"I'm saying that using a client centered approach will help to take the possible preventive measure we can take...nurses will benefit in the sense that when you do something very well you feel good about yourself, that you have done this very well. You know that it helps you to feel fulfilled at the end of the day (Detan)".

"Primary health care facilities will be a better patronised place, if the community sees that the nurses respect and value their involvement in their work (Elizabeth)".

\section{Discussion}


Just like any other human enterprise, PCC brings about changes and transformation that are difficult to come by and are problematic to positively reaping the benefits. It requires re-engineering or re-imagining and re-designing. Thus, complete responsibility is required to revolutionise the healthcare service to more patient-centeredness in PHC.

The findings from this study show that the majority of qualified nurses end-up leaving rural PHC due to a number of factors such as poor remuneration and lack of incentive, excessive workload, poor working conditions, work related stress and lack of motivation and support. These factors affect the nurses negatively leading to poor demonstration and adoption of PCC approaches in the delivery of healthcare services to patients. It was also found that nurses often bear sole responsibility for patients in the rural PHC setting which leaves them with many responsibilities. It may seem simple globally to integrate PCC into the PHC system for service delivery in rural areas; however, the complexity involved in the integration of PCC into the Nigerian healthcare system has been revealed from the findings of this study. In fact, $89 \%$ of the rural PHC nurses still retain patients' care as a way of showing that they are experts in health care $[66,67]$. This study found this to be a threat to the conventional way of organizing healthcare delivery services around patients' need for a better health outcome.

PCC requires a change from the traditional quality improvement model on PHC to a continuous, unrelenting process of change and through re-designing and the re-imagination of practice by the replacement of old practice patterns and processes with a completely new mind-set. This transformation should include new scheduling and access arrangements, and new coordination arrangements in partnership with the PHC system. This can be achieved by integrating other areas such as group visits, new methods of evidence evaluation at care points, improved quality of activities, development of team-based care, practice management changes engaging patients in new engagement strategies, and the use of information systems and technology [68].

Practicing PCC in PHC may solve a lot of healthcare-related problems such as poor health outcomes, cost of service, and spread of communicable and noncommunicable diseases among others. However, it is poorly demonstrated in PHC due to the lack of standards of practice enforcement. Transformation is a slow and painful undertaking, occurring at an unsteady and unpredictable pace. This leads to PHC system fatigue midway through the implementation phases of PCC by the healthcare providers. The magnitude and pace required to produce transformation and change in PCC require the transition to be managed prudently to avoid staff burn-out, staff turnover, and financial distress in the healthcare system. This study is similar to studies reported by Patel, Jaen, Stange, Miller, Crabtree and Nutting $[68,69]$.

The transformation required in the PHC healthcare system is echoed in the nursing profession generally. It requires competence among the nurses in the delivery of care. The majority of the nurses are more task-oriented due to work overload, whilst less focused on the patient. Nurses revealed that the challenges of less involvement with the patient are caused by the dearth of knowledge of the concept of PCC practice. This is similar to the study conducted by Flagg [70].

Additionally, poorly integrated PCC in PHC healthcare facilities is a major contributing factor to the increase in CDs and NCDs in the nation. This is because access to essential, high quality healthcare services is still a big challenge in Nigeria. According to the World Health Organization (WHO), approximately 400 million people worldwide received poor quality health care. In addition, there is unequal improvement in the healthcare system service [71, 72]. This is despite the efforts of the international collaboration on health regulations to strengthen health systems in low-and middle-income countries [13, 15].

PCC implementation is still a challenge in nursing practice despite policy makers' and government endorsements of PCC. Although these findings revealed numerous sources of the challenges facing nurses in the implementation and practice of PCC, it was revealed that some of these challenges emanated from both the organisational structures and the professional nurses themselves. The nurses were found to cause much of the resistance to the implementation of PCC. In addition, the lack of accountability from the nurses contributed to the poor implementation of PCC in PHC. It is therefore recommended that nurses should take responsibility for their actions towards patient health care outcomes and encourage nurse-patient trust in order to improve quality healthcare using the PCC approach. This will provide further protection for the institution, the nurse and the patient from unsafe practices.

It is essential to emphasise the accountability of the nurses as part of the healthcare service delivery in the rural PHC[73]. Accountability is a key component of perception. That is, nurses should be held accountable for their own decisions and actions. In addition, governments should pay much more attention to the dimension of healthcare in PHC facilities and nursing [74, 75]. Dignity and compassion should be emphasised and driven by the growing concern within the nursing fraternity. This would help PHC regain what it has "lost", as its quality has been inconsistent across different countries, regional divisions within countries and even globally [76]. Thus, the true meaning of compassionate care has been a subject of discussion specifically on how its teaching and measurement can be done [77-79]. The key question is how do we teach compassion to nursing students and professional nurses? Although compassion is included in the nursing curriculum, it is one component that is less prominent than the technical components in the nursing profession, as it lacks clear measurement tools for its effectiveness [80, 81].

Accountability is a personal responsibility that healthcare professionals should embrace as a continuous service to themselves and to their patients. Adamson and Dewar [82] stressed the importance and vitality of how for example nursing should be supported to develop compassionate skills and knowledge in caring for patients. Incorporating compassionate skills in the training and work environment through in-service education can improve the PCC model and PHC facilities. Moreover, nurses do not work in isolation within the healthcare system but with the support from other disciplines. There is a need for interdisciplinary collaborative team work. This collaborative drive is further encouraged by the WHO framework for action on inter-professional education and collaborative practice as reported by [83]. For effective delivery of the PCC model in the healthcare system, a comprehensive service by partnering with patients, their families and friends needs to be incorporated in the nursing care to offer quality healthcare service [84].

\section{Strength And Limitation}


Even though this study involved direct observation in the reality of nursing care practice in the PHC setting, it was not without limitations. The main limitation is that perception from the other healthcare professionals and the patients under care at the PHC was not investigated. It is therefore recommended that further studies be done to include other healthcare professionals and patients in the public healthcare system.

\section{Conclusion}

The study confirmed that nurses are faced with challenges in the implementation of PCC that reinforce the need for adequate management support, education and training, as well as internal motivation. This will help to improve the quality of healthcare delivery in the PHC facilities. Transformation to PCC requires time, effort and the availability of financial resources and reimbursement during the transitional period. Therefore, the provision of adequate financial resources should be ensured in the PHC facilities. To achieve transformative health care, the customisation of approaches to practice should be encouraged such that the same approach is not used for all situations.

\section{Abbreviations}

PHC: Primary Health Care; PCC: Patient-centered care; LGAs: Local government areas; WHO: World Health Organization; LMICs: Low and middle-income countries; NCDs: Non-communicable diseases; LGHC: Local government health care; SMOH: State ministries of health; FMOH: Federal ministries of health; EMR: Electronic medical records and FGD: Focus group discussions.

\section{Declarations}

\section{Availability of data and materials}

All data analyzed for this study is available in this paper.

\section{Ethical approval and consent to participate}

Approval for this study was obtained from the University of KwaZulu-Natal Humanities Social Sciences Research Ethics Committee with Protocol reference number: HSS/1772/018D. In addition, permission was sought from the Osun State Primary Health Care development board. All the participants received both verbal and written consent to participate as well as information about the study content. Participants' participation was voluntary.

\section{Consent for publication}

Not applicable

\section{Author contributions}

AL conducted the investigation, conceptualized the paper, and prepared the manuscript draft, and Dr. EM read and reviewed the paper. Both authors agreed on the final versions of the manuscript.

\section{Competing interests}

The authors declare no conflicts of interest.

\section{Funding}

This project received no specific funding from any organization.

\section{Questionnaire}

The interview questions used in the study was developed for this study.

\section{Acknowledgments}

The authors acknowledge all the study participants, the School of Nursing and Public, for the resources made available to finish this project. This publication was also supported by the Fogarty International Center (FIC), NIH Common Fund, Office of Strategic Coordination, Office of the Director (OD/OSC/CF/NIH), Office of AIDS Research, Office of the Director (OAR/NIH), National Institute of Mental Health (NIMH/NIH) of the National Institutes of Health under Award Number D43TW010131. The research reported is solely the authors' responsibility and does not necessarily represent the National Institutes of Health's official views. 


\section{References}

1. Berenson RA, Hammons T, Gans DN, Zuckerman S, Merrell K, Underwood WS, et al. A house is not a home: Keeping patients at the center of practice redesign. Health Aff. 2008;27(5):1219-30.

2. Backer LA. Building the case for the patient-centered medical home. Family Practice Management. 2009;16(1):14-8.

3. Davis K, Schoenbaum SC, Audet AM. A 2020 vision of patient-centered primary care. J Gen Intern Med. 2005;20(10):953-7.

4. Fisher ES. Building a medical neighborhood for the medical home. The New England Journal of Medicine. 2008;359(12):1202.

5. Grumbach K, Bodenheimer T. A primary care home for Americans: Putting the house in order. JAMA. 2002;288(7):889-93.

6. Kellerman R, Kirk L. Principles of the patient-centered medical home. Am Fam Physician. 2007;76(6):774-5.

7. Fanjiang G, Grossman JH, Compton WD, Reid PP. Building a Better Delivery System: A New Engineering/Health Care Partnership. Washington, D.C, USA: National Academies Press; 2005.

8. Grumbach K, Bodenheimer T. Can health care teams improve primary care practice? JAMA. 2004;291(10):1246-51.

9. Engel GL. The need for a new medical model: A challenge for biomedicine. Science. 1977;196(4286):129-36.

10. Farre A, Rapley T. The new old (and old new) medical model: Four decades navigating the biomedical and psychosocial understandings of health and illness. Healthcare. 2017;5(88):1-9.

11. Mead N, Bower P. Patient-centred consultations and outcomes in primary care: A review of the literature. Patient Educ Couns. 2002;48(1):51-61.

12. Mahendradhata Y, Souares A, Phalkey R, Sauerborn R. Optimizing patient-centeredness in the transitions of healthcare systems in low-and middle-income countries. BMC Health Services Research. 2014;14(386):1-6.

13. World Health Organization. Human Resources for Health Action Framework for the Western Pacific Region (2011-2015). Switzerland World Health Organization Western Pacific Region; 2012.

14. Goodwin N. Understanding integrated care: The Role of Information and Communication Technology. International Journal of Integrated Care. 2016;16(4):1-4.

15. World Health Organization. Framework on integrated, people-centred health services. World Health Organization [Internet]. 2016 28th March; (1). Available from: http://apps.who.int/gb/ebwha/pdf_files/wha69/a69_39-en.pdf.

16. Scott KW, Jha AK. Putting quality on the global health agenda. N Engl J Med. 2014;371(1):3-5.

17. Langley GJ, Moen RD, Nolan KM, Nolan TW, Norman CL, Provost LP. The Improvement Guide: A Practical Approach to Enhancing Organizational Performance. San Francisco: John Wiley \& Sons; 2009.

18. Bodenheimer T, Wagner EH, Grumbach K. Improving primary care for patients with chronic illness. JAMA. 2002;288(14):1775-9.

19. Bodenheimer T, Wagner EH, Grumbach K. Improving primary care for patients with chronic illness: The chronic care model, Part 2. JAMA. 2002;288(15):1909-14.

20. Brody H. Relationship-centered care: Beyond the finishing school. Michigan: Am Board Family Med; 1995.

21. Marvel MK, Epstein RM, Flowers K, Beckman HB. Soliciting the patient's agenda: Have we improved? JAMA. 1999;281(3):283-7.

22. Tresolini C, Force P-FT. Health professions education and relationship-centered care. 8. San Francisco: Pew Health Professions Commission; 1994.

23. Crosson JC, Stroebel C, Scott JG, Stello B, Crabtree BF. Implementing an electronic medical record in a family medicine practice: communication, decision making, and conflict. The Annals of Family Medicine. 2005;3(4):307-11.

24. Kush RD, Helton E, Rockhold FW, Hardison CD. Electronic health records, medical research, and the Tower of Babel. N Engl J Med. 2008.

25. Hersh W. Health care information technology: Progress and barriers. JAMA. 2004;292(18):2273-4.

26. DesRoches CM, Campbell EG, Rao SR, Donelan K, Ferris TG, Jha A, et al. Electronic health records in ambulatory care-A national survey of physicians. N Engl J Med. 2008;359(1):50-60.

27. Reid RJ, Coleman K, Johnson EA, Fishman PA, Hsu C, Soman MP, et al. The group health medical home at year two: Cost savings, higher patient satisfaction, and less burnout for providers. Health Aff. 2010;29(5):835-43.

28. Maeng DD, Khan N, Tomcavage J, Graf TR, Davis DE, Steele GD. Reduced acute inpatient care was largest savings component of Geisinger Health System's patient-centered medical home. Health Aff. 2015;34(4):636-44.

29. Maeng DD, Graham J, Graf TR, Liberman JN, Dermes NB, Tomcavage J, et al. Reducing long-term cost by transforming primary care: Evidence from Geisinger's medical home model. The American Journal of Managed Care. 2012;18(3):149-55.

30. Paustian ML, Alexander JA, El Reda DK, Wise CG, Green LA, Fetters MD. Partial and incremental PCMH practice transformation: Implications for quality and costs. Health Serv Res. 2014;49(1):52-74.

31. Moore L, Britten N, Lydahl D, Naldemirci Ö, Elam M, Wolf A. Barriers and facilitators to the implementation of person-centred care in different healthcare contexts. Scand J Caring Sci. 2017;31(4):662-73.

32. Lateef AM, Mhlongo EM. A Literature Review on People-Centered Care and Nursing Practice in Primary Health Care Setting. Global Journal of Health Science. 2020;12(2):23-40.

33. Mitchell P, Wynia M, Golden R, McNellis B, Okun S, Webb CE, et al. Core Principles \& Values of Effective Team-Based Health Care. Washington D.C: Institute of Medicine of the National Academies; 2012.

34. Magill MK, Ehrenberger D, Scammon DL, Day J, Allen T, Reall AJ, et al. The cost of sustaining a patient-centered medical home: Experience from 2 states. The Annals of Family Medicine. 2015;13(5):429-35. 
35. Abdulraheem IS, Olapipo AR, Amodu MO. Primary health care services in Nigeria: Critical issues and strategies for enhancing the use by the rural communities. Journal of Public Health Epidemiology. 2012;4(1):5-13.

36. Onwujekwe O. Moving Nigeria from low coverage to universal health coverage: Health system challenges, equity and the.evidence-base 2013 [Available from:

https://www.researchgate.net/profile/Obinna_Onwujekwe/publication/317267470_Moving_Nigeria_from_low_coverage_to_universal_health_coverage_na! base/links/592f1958a6fdcc89e7773723/Moving-Nigeria-from-low-coverage-to-universal-health-coverage-national-health-system-challenges-equity-andthe-evidence-base.pdf.

37. World Health Organization. Declaration of Alma-Ata International Conference on Primary Health Care, Alma-Ata, USSR, 6-12 1978 [Available from: https://www.who.int/publications/almaata_declaration_en.pdf?ua=1.

38. Lambo E. Primary health care: Realities, challenges and the way forward, A paper presented at the first annual primary health care lecture, Abuja. Abuja, Nigeria2015 [Available from: http://nigeriahealthwatch.com/wp-content/uploads/bsk-

pdfmanager/1160_2015_Primary_Health_Care_Presentation_Final_NPHCDA_1216.pdf.

39. Aregbeshola BS, Khan SM. Primary health care in Nigeria: 24 years after Olikoye Ransome-Kuti's Leadership. Frontiers in Public Health. $2017 ; 5(48): 1-2$.

40. Aregbeshola B. Towards universal primary health care in Nigeria 2019 [Available from:

file://C:/Users/princ/Desktop/Towards\%20universal\%20primary\%20health\%20care\%20in\%20Nigeria\%20_\%20socialprotection.org.html.

41. Federal Ministry of Health. National health facility survey 2016 final report. Abuja: Federal Ministry of Health; 2016.

42. Rao M, Pilot E. The missing link-the role of primary care in global health. Global Health Action. 2014;7(1):1-7.

43. Buykx P, Humphreys JS, Tham R, Kinsman L, Wakerman J, Asaid A, et al. How do small rural primary health care services sustain themselves in a constantly changing health system environment? BMC Health Services Research. 2012;12(81):1-7.

44. Loue S. Community health advocacy. Journal of Epidemiology Community Health. 2006;60(6):458-63.

45. Department of Economic and Social Affairs Office for ECOSOC Support and Coordination. Achieving Sustainable Development and Promoting Development Cooperation. New York: United Nations; 2008.

46. Adewoyin J, Ogunyemi S, Muibi K, Fasote O, Halilu S, Alaga T. Spatial Distribution and Accessibility of Primary Health Centre in Ife East Local Government of Osun State, Nigeria. Journal of Scientific Research Reports. 2016;9(7):1-9.

47. Adeyemo D. Local government and health care delivery in Nigeria: A case study. Journal of Human Ecology. 2005;18(2):149-60.

48. Olujimi J. Accessibility of rural dwellers to health care facilities in Nigeria: The Owo region experience. Pakistan Journal of Social Sciences. 2007;4(1):4455.

49. Oyekale AS. Assessment of primary health care facilities' service readiness in Nigeria. BMC Health Services Research. 2017;17(172):1-12.

50. MacDonald C. Understanding participatory action research: A qualitative research methodology option. The Canadian Journal of Action Research. 2012;13(2):34-50.

51. Mathieson L. Synergies in Critical Reflective Practice and Science: Science as Reflection and Reflection as Science. Journal of University Teaching Learning Practice. 2016;13(2):1-15.

52. National Bureau Statistics. Demographic Statistics Bullettin 2017 [Available from: file:///E:/Demographic\%20Statistics\%20Bulletin\%202017.pdf.

53. Sanni L. Distribution pattern of healthcare facilities in Osun State, Nigeria. Ethiopian Journal of Environmental Studies Management. 2010;3(2):65-76.

54. Morse JM. The significance of saturation. SAGE Social Science Collection. 1995;5(2):147-9.

55. Charmaz K. Constructing Grounded Theory: A Practical Guide Through Qualitative Analysis. London: Sage; 2006.

56. Saldaña J. The Coding Manual for Qualitative Researchers. 3rd ed. ed. Washington: Sage; 2015.

57. Braun V, Clarke V. What can "thematic analysis" offer health and wellbeing researchers? International Journal of Qualitative Studies on Health Well-being. 2014;9(26152):1-2.

58. Leung L. Validity, reliability, and generalizability in qualitative research. Journal of Family Medicine Primary Care. 2015;4(3):324-7.

59. Noble H, Smith J. Issues of validity and reliability in qualitative research. Evidence-Based Nursing. 2015;18(2):34-5.

60. Fawcett J, Garity J. Evaluating Research for Evidence-Based Nursing Practice. Philadelphia: F.A. Davis Company; 2008.

61. Korstjens I, Moser A. Series: practical guidance to qualitative research. Part 4: trustworthiness and publishing. European Journal of General Practice. 2018;24(1):120-4.

62. Guba EG, Lincoln YS. Competing Paradigms in Qualitative Research. Handbook of Qualititaive Research. Thousand Oaks: Sage; 1994.

63. Shenton AK. Strategies for ensuring trustworthiness in qualitative research projects. Education for linformation. 2004;22(2):63-75.

64. Anney VN. Ensuring the quality of the findings of qualitative research: Looking at trustworthiness criteria. Journal of Emerging Trends in Educational Research Policy Studies (JETERAPS). 2014;5(2):272-81.

65. Polit DF, Beck CT. Nursing Research: Principles and Methods. 7th ed. ed. New York: Lippincott Williams \& Wilkins; 2004.

66. Kieft RA, de Brouwer BB, Francke AL, Delnoij DM. How nurses and their work environment affect patient experiences of the quality of care: A qualitative study. BMC Health Services Research. 2014;14(249):1-10.

67. World Health Organization. A vision for primary health care in the 21st century: Towards universal health coverage and the Sustainable Development Goals. World Health Organization; 2018.

68. Nutting PA, Miller WL, Crabtree BF, Jaen CR, Stewart EE, Stange KC. Initial lessons from the first national demonstration project on practice transformation to a patient-centered medical home. The Annals of Family Medicine. 2009;7(3):254-60.

Page $11 / 12$ 
69. Patel NK, Jaén CR, Stange KC, Miller WL, Crabtree BF, Nutting P. Patient centered medical home: A journey not a destination. Geriatrics Models of Care. USA: Springer; 2015. pp. 155-62.

70. Flagg AJ. The role of patient-centered care in nursing. Nursing Clinics. 2015;50(1):75-86.

71. World Health Organization. People-centred and integrated health services: An overview of the evidence: Interim report. Geneva: WHO; 2015.

72. Kumar S, Preetha G. Health promotion: An effective tool for global health. Indian Journal of Community Medicine: Official Publication of Indian Association of Preventive Social Medicine. 2012;37(1):5-12.

73. Fix GM, VanDeusen Lukas C, Bolton RE, Hill JN, Mueller N, LaVela SL, et al. Patient-centred care is a way of doing things: How healthcare employees conceptualize patient-centred care. Health Expect. 2018;21(1):300-7.

74. Department of Health. High Quality Care for All - NHS Next Stage Review Final Report. London: Department of Health; 2008.

75. Smith S, Dewar B, Pullin S, Tocher R. Relationship centred outcomes focused on compassionate care for older people within in-patient care settings. Int J Older People Nurs. 2010;5(2):128-36.

76. Maben J, Griffiths PD. Nurses in Society: starting the debate: National Nursing Research Unit at King's College London; 2008.

77. Bradshaw A. Measuring nursing care and compassion: The McDonaldised nurse? J Med Ethics. 2009;35(8):465-8.

78. Papadopoulos I, Ali S. Measuring compassion in nurses and other healthcare professionals: An integrative review. Nurse Educ Pract. 2016;16(1):133-9.

79. Straughair C. Exploring compassion: implications for contemporary nursing. Part 1. British Journal of Nursing. 2012;21(3):160-4.

80. Shea S, Wynyard R, West E, Lionis C. Reaching a consensus in defining and moving forward with the science and art of compassion in healthcare. Journal of Holistic Healthcare. 2011;8(3).

81. Firth-Cozens J, Cornwell J. Enabling compassionate care in acute hospital settings. London: The King's Fund; 2009.

82. Adamson E, Dewar B. Compassion in the nursing curriculum: Making it more explicit. Journal of Holistic Healthcare. 2011;8(3):42-55.

83. Gilbert JH, Yan J, Hoffman SJ. A WHO report: Framework for action on interprofessional education and collaborative practice. J Allied Health. 2010;39(3):196-7.

84. Pelzang R, Wood B, Black S. Nurses' understanding of patient-centred care in Bhutan. British Journal of Nursing. 2010;19(3):186-93.

\section{Supplementary Files}

This is a list of supplementary files associated with this preprint. Click to download.

- Additionalfile.docx 